\title{
Etude ALGOFINE-2
}

\section{ANALGESIE AU SUFENTANIL PAR VOIE INTRA NASALE VERSUS MORPHINE IV AUX URGENCES}

Etude randomisée, contrôlée en double aveugle, double placebo, multicentrique

\section{Intranasal Sufentanil analgesia}

versus Morphine intravenous in Emergency room

A multi-center, randomized, controlled, double-blind, double placebo trial

\section{Plan d'analyse statistique de l'étude}

(Statistical analysis plan of the study)
Investigateur coordonnateur :
Dr Marc Blancher
Promoteur :
$\mathrm{CHU}$ de Grenoble
Responsable scientifique :
Dr Raphael Briot

Centre d'Investigation Clinique

Auteur du plan d'analyse statistique :

Jean-Louis Quesada 
ALGOFINE-2 - Intranasal Sufentanil analgesia versus Morphine intravenous in Emergency room Statistical analysis plan

1. ADMINISTRATIVE INFORMATION

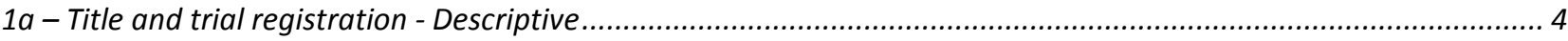

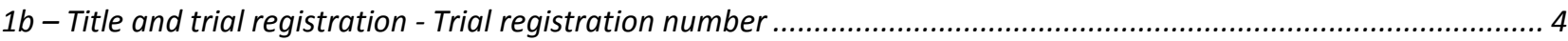

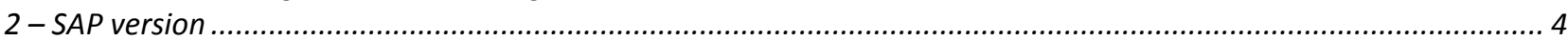

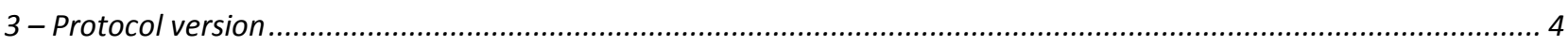

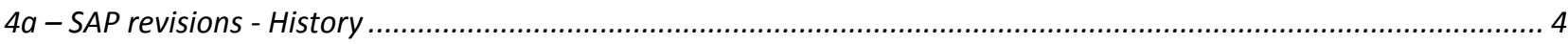

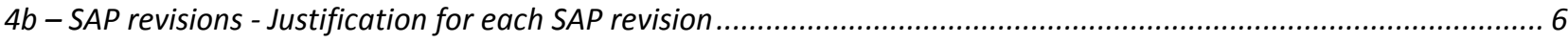

$4 c-S A P$ revisions - Timing of SAP revisions in relation to interim analyses ........................................................ 7

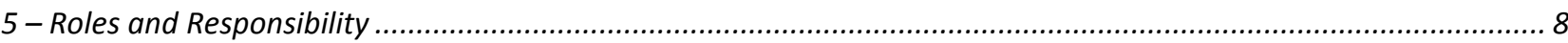

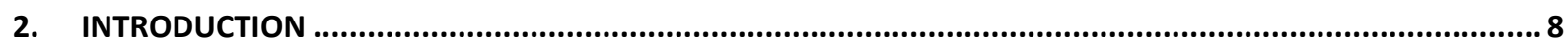

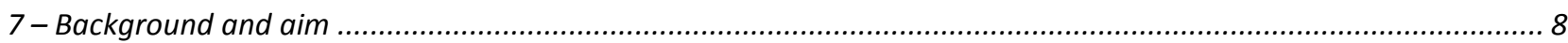

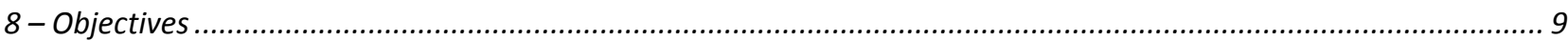

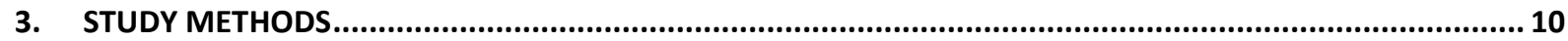

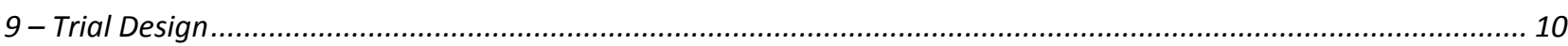

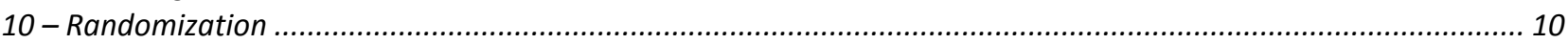

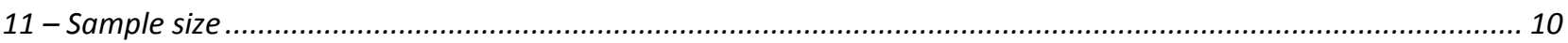

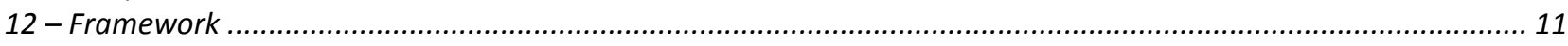

$13 a$ - Statistical interim analyses and stopping guidance - Information ........................................................... 11

$13 b$ - Statistical interim analyses and stopping guidance - planned adjustment ............................................. 11

$13 \mathrm{c}$ - Statistical interim analyses and stopping guidance - Details of guidelines ................................................. 11

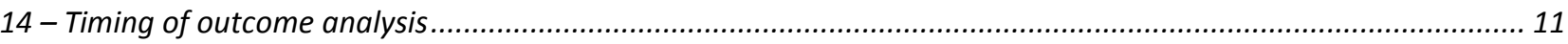

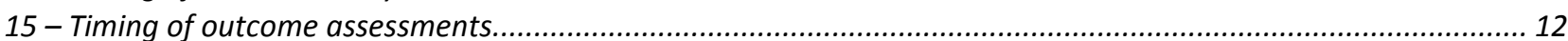

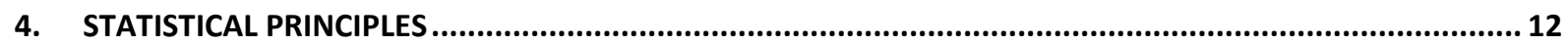

16 - Confidence intervals and $P$ values - Level of statistical significance............................................................. 12

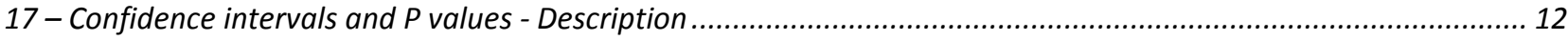

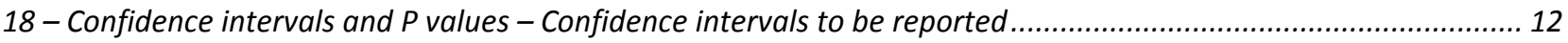

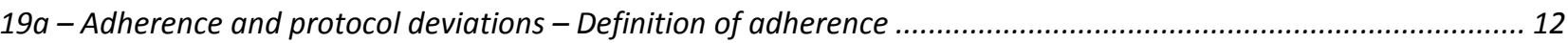

$19 \mathrm{~b}$ - Adherence and protocol deviations - Description of adherence .................................................................... 13

$19 d$-Adherence and protocol deviations - Description of protocol deviations to be summarized .............................. 13

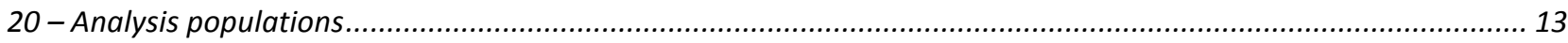

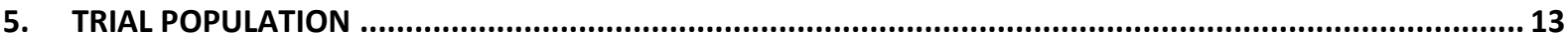

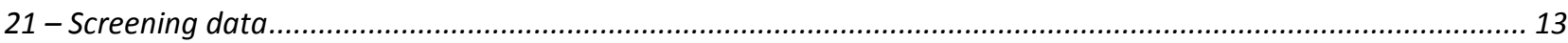

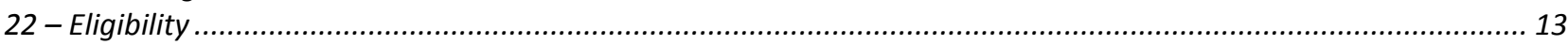

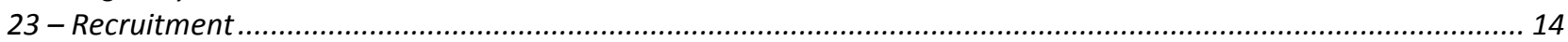

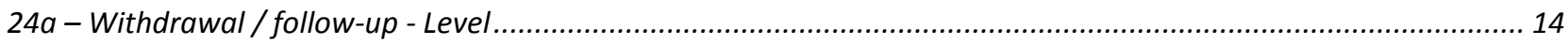

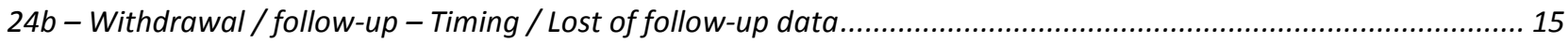

$24 c$ - Withdrawal / follow-up - Reasons and details.................................................................................... 15

$25 a$ - Baseline patient characteristics - List of baseline patient characteristics to be summarized ............................. 15

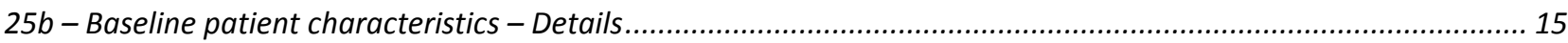

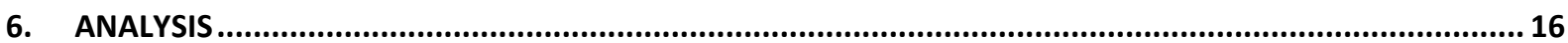

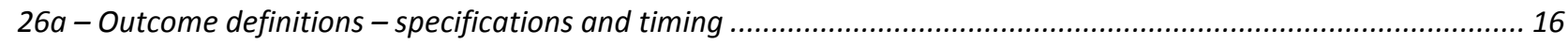

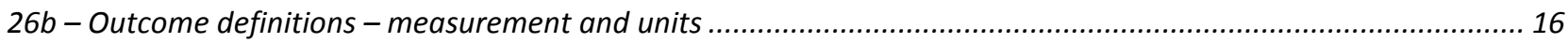

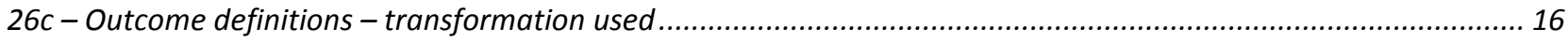

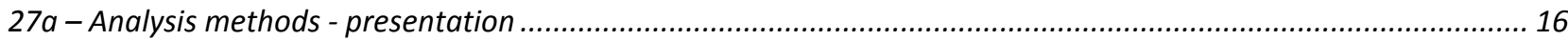

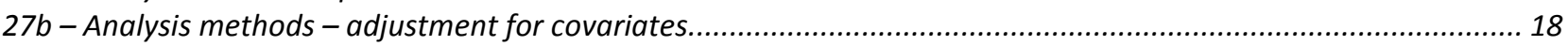

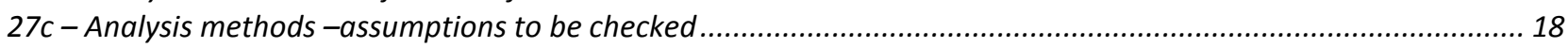

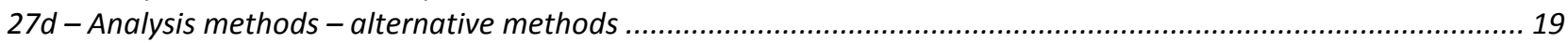

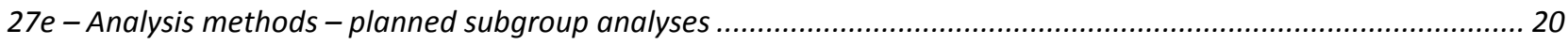

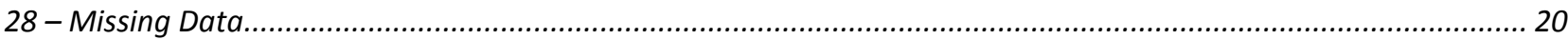

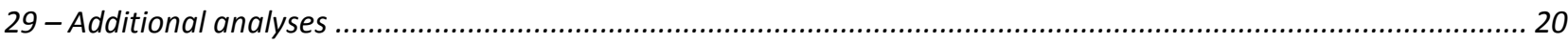

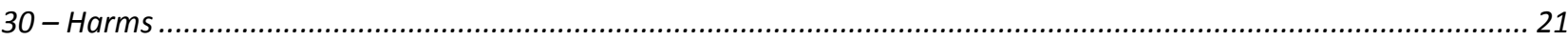


ALGoFINE-2 - Intranasal Sufentanil analgesia versus Morphine intravenous in Emergency room

Statistical analysis plan

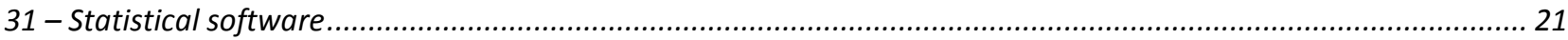

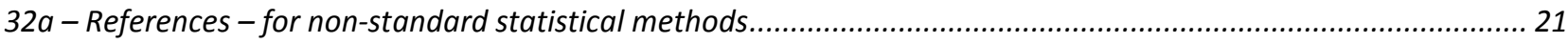

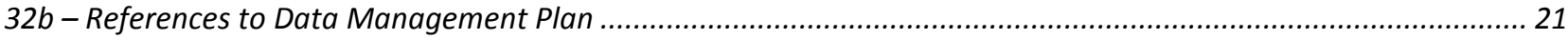

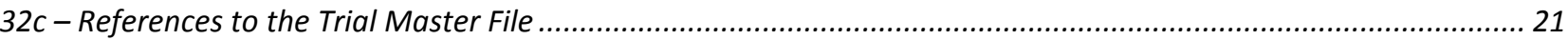

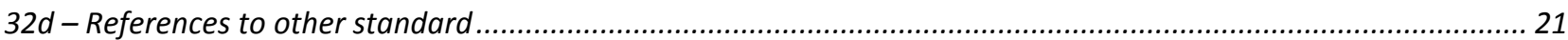

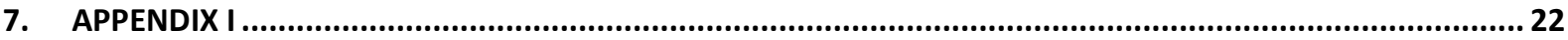

Template of table of descriptive analysis at the inclusion visit .....................................................................22

Templates of table of the principal outcomescales analysis between the inclusion (TO) and the visit

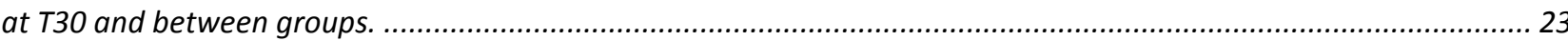

Templates of tables of scales analysis between the inclusion (TO) and the visit at T10 or T20 and

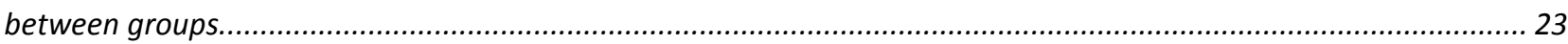

Templates of tables of scales analysis between the inclusion (TO) and the visit at T10 by groups.............................. 23

Templates of tables of scales analysis between the inclusion (TO) and the visit at T20 by groups.............................. 24.

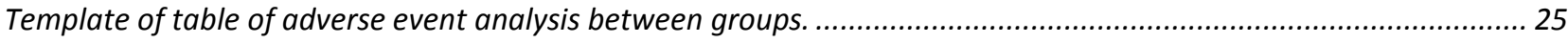

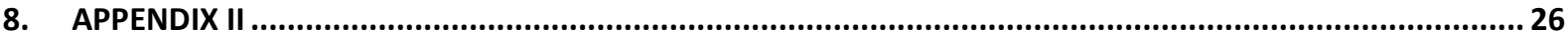

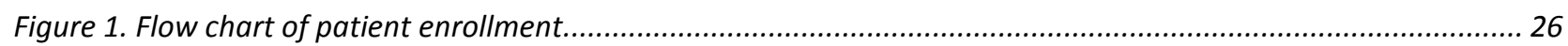


The analysis plan for this randomized trial was formatted to conform to the 2017 version of the recommendations "Guidelines for the content of statistical analysis plans in clinical trials".

\section{Administrative Information}

\section{$\underline{1 \mathrm{a}-\text { Title and trial registration - Descriptive }}$}

Statistical analysis plan for the Algofine-2 study ( Intranasal Sufentanil analgesia versus Morphine intravenous in Emergency room »): A multi-center, randomized, controlled, double-blind, double placebo trial.

\section{$\underline{1 b}$ - Title and trial registration - Trial registration number}

Trial Registration : EudraCT registration number : 2013-001665-16, Date 2013-08-01

\section{$\underline{2-S A P}$ version}

Version 3.0 of the statistical analysis plan was carried out after the blind review of May 12, 2016 in the presence of Dr Marc Blanchet (Investigator, coordinator of the study), Dr Raphael Briot (Scientific Manager of the study), Cyrielle Clapé (CRA, Project Manager), Dr Damien Viglino (CCA) and Jean-Louis Quesada (Biostatistician), in accordance with the database freezing procedure.

This analysis plan was presented during the methodology EPP staff (Evaluation of Professional Practices) of the CIC of June 27, 2016. A sensibility analysis has been proposed, in accordance with the latest JAMA recommendations, to complete the analysis of the primary endpoint performed on the per protocol population by validating the results on the Intent to Treat (ITT) population.

\section{$\underline{3-\text { Protocol version }}$}

This document has been written based on information contained in the study protocol MS4 version 10, dated October $22^{\text {nd }}, 2015$.

$\underline{4 a-S A P ~ r e v i s i o n s ~-~ H i s t o r y ~}$

\begin{tabular}{|c|c|c|l|c|}
\hline $\begin{array}{c}\text { Protocol } \\
\text { version }\end{array}$ & $\begin{array}{c}\text { Updated SAP } \\
\text { Version number }\end{array}$ & $\begin{array}{c}\text { Section number } \\
\text { changed }\end{array}$ & \multicolumn{1}{|c|}{ Description of and reason for change } & Date \\
\hline 7.0 & 1.0 & - & $\begin{array}{l}\text { Initial submission of the protocol to the Ethics } \\
\text { Comity (French CPP) and French ANSM authorities. }\end{array}$ & $31 / 07 / 2013$ \\
\hline
\end{tabular}




\begin{tabular}{|c|c|c|c|c|}
\hline \multirow[t]{7}{*}{$\begin{array}{c}8.0 \\
\text { MS2 }\end{array}$} & \multirow[t]{7}{*}{2.0} & $\begin{array}{l}\text { - Summary } \\
\text { Section "main } \\
\text { judgment } \\
\text { criterion" }\end{array}$ & $\begin{array}{l}\text { - Clarification of the main judgment criterion : } \\
\text { Variation of the numerical scale of pain (EN at T30- } \\
\text { EN at TO) }\end{array}$ & \multirow[t]{7}{*}{ 29/04/2014 } \\
\hline & & $\begin{array}{l}\text { - Summary } \\
\text { Section "target } \\
\text { population" }\end{array}$ & $\begin{array}{l}\text { - Clarification of the target population: distinction } \\
\text { between the analysis population related to the } \\
\text { main objective }(2 \times 110) \text { and that linked to the } \\
\text { secondary objective } n^{\circ} 5 \text { ( } 30 \text { complementary } \\
\text { subjects). }\end{array}$ & \\
\hline & & $\begin{array}{l}\text { - Summary } \\
\text { Section "Data } \\
\text { processing" }\end{array}$ & $\begin{array}{l}\text { - Precision for the non-inferiority analysis: the } \\
\text { threshold selected for this analysis will be } 1.3 \text {. } \\
\text { - Precision for the statistical threshold of } \\
\text { significance retained for the non-inferiority analysis } \\
(2.5 \%) \text {. } \\
\text { - General description of the descriptive and } \\
\text { comparative analysis of secondary objectives. }\end{array}$ & \\
\hline & & $\begin{array}{l}\text { - Chapter II } \\
\text { Section } \\
\text { "Objectives" }\end{array}$ & $\begin{array}{l}\text { - Modifications and addition of objectives and } \\
\text { secondary criteria. }\end{array}$ & \\
\hline & & $\begin{array}{l}\text { - Chapter IV } \\
\text { Section "sample } \\
\text { size" }\end{array}$ & $\begin{array}{l}\text { - Changes in sample size calculation: Change in the } \\
\text { common standard deviation ( } 2.1 \text { to } 2.8) \text { related to } \\
\text { the main criterion based on the publication } \\
\text { "Birnbaum A., Esses D., Randomized Double-Blind } \\
\text { Placebo-Controlled Trial of Two Intravenous } \\
\text { Morphine Dosages }(0.10 \mathrm{mg} / \mathrm{kg} \text { and } 0.15 \mathrm{mg} / \mathrm{kg} \text { ) in } \\
\text { Emergency Department Patients With Moderate to } \\
\text { Severe Acute Pain. } 49: 445-453 \text { (2007)" and the } \\
\text { reduction of the power of the analysis to } 80 \% \text {. }\end{array}$ & \\
\hline & & $\begin{array}{l}\text { - Chapter IX } \\
\text { Section } \\
\text { "Replacement of } \\
\text { missing data" }\end{array}$ & $\begin{array}{l}\text { - Clarification on the replacement of missing data: } \\
\text { For per-protocol population analysis, no } \\
\text { replacement of missing data is considered for the } \\
\text { analysis of the primary endpoint. } \\
\text { With regard to a possible intention-to-treat } \\
\text { analysis, a multiple imputation method would be } \\
\text { implemented. }\end{array}$ & \\
\hline & & $\begin{array}{l}\text { - Chapter IX } \\
\text { Section } \\
\text { "Statistical tests" }\end{array}$ & $\begin{array}{l}\text { - Clarification of Statistical Analysis: For each } \\
\text { objective of the study, details of the statistical tests } \\
\text { used and their justifications. } \\
\text { - Precision: A detailed analysis plan covering all } \\
\text { objectives may be completed before the study } \\
\text { database is frozen, in conjunction with the scientific } \\
\text { steering committee of the study. }\end{array}$ & \\
\hline
\end{tabular}




\begin{tabular}{|c|c|c|l|l|}
\hline-3.0 & $\begin{array}{l}\text { "Superiority } \\
\text { analysis" }\end{array}$ & $\begin{array}{l}\text { - Clarification of Statistical Analysis: The evaluation } \\
\text { of the superiority of intra-nasal Sufentanil } \\
\text { compared to the reference treatment will be used if } \\
\text { non-inferiority is demonstrated. }\end{array}$ & $12 / 05 / 2016$ \\
\hline- & 3.1 & $\begin{array}{l}\text { "Primary } \\
\text { endpoint } \\
\text { analysis" }\end{array}$ & $\begin{array}{l}\text { - Clarification of Statistical Analysis: A sensibility } \\
\text { analysis has been proposed by the methodology } \\
\text { EPP staff to complete the analysis of the primary } \\
\text { endpoint performed on the per protocol population } \\
\text { by validating the results on the Intent to Treat (ITT) } \\
\text { population. }\end{array}$ & $27 / 06 / 2016$ \\
\hline- & - & $\begin{array}{l}\text { SAP reviewed to take account of the new Guidelines } \\
\text { (JAMA, 2017). } \\
\text { - Clarification of Statistical Analysis: The reviewer of } \\
\text { the manuscript proposed to complete the analysis } \\
\text { with a linear regression that adjusts for baseline } \\
\text { pain score and site }\end{array}$ & $13 / 05 / 2019$ \\
\hline
\end{tabular}

\section{$\underline{4 b-S A P}$ revisions - Justification for each SAP revision}

The statistical analysis plan (SAP) of the clinical protocol has been updated April 29, 2014, to adapt it to:

- the clarification of the main judgment criterion : Variation of the numerical scale of pain (EN at T30 - EN at T0),

- precision for the non-inferiority analysis : the threshold selected for this analysis will be 1.3 .

- precision for the statistical threshold of significance retained for the non-inferiority analysis $(2.5 \%)$.

- general description of the descriptive and comparative analysis of secondary objectives.

- the clarification of the target population : distinction between the analysis population related to the main objective $(2 \times 110)$ and that linked to the secondary objective $\mathrm{n}^{\circ} 5$ (30 complementary subjects).

- the modifications and addition of objectives and secondary criteria.

- the modification of the sample size according to the change in the common standard deviation (2.1 to 2.8) related to the main criterion based on the publication "Birnbaum A., Esses D., Randomized Double-Blind Placebo-Controlled Trial of Two Intravenous Morphine Dosages $(0.10 \mathrm{mg} / \mathrm{kg}$ and $0.15 \mathrm{mg} / \mathrm{kg})$ in Emergency Department Patients With Moderate to Severe Acute Pain. 49:445-453 (2007)" and the reduction of the power of the analysis to $80 \%$. 
- Clarification on the replacement of missing data: For per-protocol population analysis, no replacement of missing data is considered for the analysis of the primary endpoint.

- With regard to a possible intention-to-treat analysis, a multiple imputation method would be implemented.

- Clarification of Statistical Analysis: For each objective of the study, details of the statistical tests used and their justifications.

- Precision: A detailed analysis plan covering all objectives may be completed before the study database is frozen, in conjunction with the scientific steering committee of the study.

The Statistical Analysis Plan (SAP) of the clinical protocol was updated after the blind review on May 12, 2016, in accordance with the database freezing procedure, to incorporate a superiority analysis on the Intent to Treat (ITT) population in case of non-inferiority demonstration.

The Statistical Analysis Plan (SAP) of the clinical protocol was updated after the methodology EPP staff (Evaluation of Professional Practices) of the CIC of June 27, 2016. A sensibility analysis has been proposed, in accordance with the latest JAMA recommendations, to complete the analysis of the primary endpoint performed on the per protocol population by validating the results on the Intent to Treat (ITT) population.

The statistical analysis plan for this randomized trial was formatted May 13, 2019 to conform to the 2017 version of the recommendations "Guidelines for the content of statistical analysis plans in clinical trials" (JAMA, 2017).

\section{$\underline{4 c-S A P \text { revisions - Timing of SAP revisions in relation to interim analyses }}$}

Not applicable. 


\section{$\underline{5-\text { Roles and Responsibility }}$}

\begin{tabular}{|c|l|l|}
\hline Name & \multicolumn{1}{|c|}{ Affiliations } & Roles of SAP contributors \\
\hline $\begin{array}{c}\text { Jean-Louis } \\
\text { Quesada }\end{array}$ & $\begin{array}{l}\text { Biostatistician methodologist } \\
\text { Plurithematic Clinical Investigation } \\
\text { Center } \\
\text { (INSERM CIC P 1406) } \\
\text { CHU de Grenoble - Hôpital } \\
\text { A.Michallon } \\
\text { BP 217 } \\
\text { 38043 Grenoble Cedex 09 }\end{array}$ & $\begin{array}{l}\text { Write the SAP for the Initial } \\
\text { submission, and the updated } \\
\text { of the protocol. }\end{array}$ \\
\hline $\begin{array}{c}\text { Staff EPP } \\
\text { Plurithematic Clinical Investigation } \\
\text { Center } \\
\text { (INSERM CIC P 1406) } \\
\text { CHU de Grenoble - Hôpital } \\
\text { A.Michallon } \\
\text { BP 217 } \\
\text { 38043 Grenoble Cedex 09 }\end{array}$ & $\begin{array}{l}\text { Reviewed and anplementar } \\
\text { complem } \\
\text { the SAP. }\end{array}$ \\
\hline $\begin{array}{c}\text { Dr Marc } \\
\text { Blanchet }\end{array}$ & Principal Investigator coordinator \\
\hline $\begin{array}{c}\text { Dr Raphael } \\
\text { Briot }\end{array}$ & Manager Scientist & Approved the SAP. \\
\hline $\begin{array}{l}\text { Dr Damien } \\
\text { Viglino }\end{array}$ & Methodologist & Approved the SAP. \\
\hline
\end{tabular}

\section{Introduction}

\section{7-Background and aim}

Analgesia is one of the main objectives of the management of patients presenting in an emergency department. The traumatology is more particularly associated with acute pain episodes, this is the case at the time of the trauma but also when the traumatized area is solicited (removal of clothing, clinical or radiological examination). The Grenoble basin and the Alpine arc have the dual feature of being both densely populated in terms of population and geographically located very close to mountain areas. As a result, in addition to "classical" sports and domestic traumatology, mountain sports, and in particular winter sports, are added. If the pain symptom is particularly associated with trauma, it is also very often underestimated, which can have deleterious consequences on the clinical state of the patients. 
Reducing these post-traumatic acute pain episodes is one of the public health goals that has been clearly defined by the Ministry of Health.

Other products derived from the Morphine are usable and have a theoretical interest because they act faster. This is the case of Sufentanil, which has a shorter reaction time (60 to 120 seconds) than Morphine ${ }^{3}$.

In addition, Sufentanil has the advantage of a wider therapeutic margin than Morphine or Fentanyl. In practice, the studies carried out reveal little undesirable effects when using Sufentanil, often at doses higher than the equi-analgesia Morphine ${ }^{4,5,6}$.

Studies published so far tend to show the efficacy and safety of Sufentanil used intranasally in the management of pain in emergencies. However, there are no randomized, controlled, blinded, emergency department studies in an adult population.

(Nota: from the Paragraph "justification of the study" of the protocol)

\section{$\underline{8 \text {-Objectives }}$}

The main objective of the study is to compare the efficacy of analgesia performed by intra nasal Sufentanil compared to the reference treatment (IV Morphine).

The aim of the secondary objectives of the trial is to :

- Compare the efficacy of analgesia performed by intranasal Sufentanil compared to the reference treatment (IV Morphine) after $10 \mathrm{~min}$ and $20 \mathrm{~min}$ of treatment.

- Evaluate the efficacy of analgesia performed by intranasal Sufentanil and Morphine IV, after $10 \mathrm{~min}$ and $20 \mathrm{~min}$ of treatment.

- Compare the occurrence of adverse effects between treatment groups (Sufentanil IN versus Morphine IV).

- Evaluate the efficacy of analgesia performed by intranasal Sufentanil compared to the reference treatment (IV Morphine) after $10 \mathrm{~min}, 20 \mathrm{~min}$ and $30 \mathrm{~min}$ of treatment in the group of pre-hospital patients.

- Evaluate patient satisfaction 


\section{Study Methods}

\section{$\underline{9-T r i a l ~ D e s i g n}$}

This study is a multicentre prospective, randomized, double-blind, controlled, double placebo trial.

\section{0 - Randomization}

Randomization 1:1 in parallel groups was pre-performed in blocks of random sizes and stratified by centre. The randomization list was handed over to the central pharmacy in charge of preparing packs. The randomization list was generated usung the Nquery Advisor software version 7.0 (Statistical Solutions Ltd, Boston MA, USA).

\section{1 - Sample size}

Version 1.0 of July 312013 J-L Quesada (Protocol version 7.0 - 31/07/2013):

The number of patients to be included in the study was calculated for a non-inferiority study according to the following assumptions: The mean value of EN at 30 minutes in patients with pain $\geq 6$, relieved by Morphine is 3.7 (standard deviation of 2.2). Given an alpha risk of $2.5 \%$ and a non-inferiority threshold of 1.3 (EN standard equivalence threshold usually accepted) ${ }^{24}$. The number of subjects required, calculated using the Schuirmann ${ }^{25}$ method, is 99 in each group to be able to conclude that the evaluated treatment is non-inferior compared to the reference treatment on $\mathrm{EN}$ at 30 minutes with a power of $97 \%$.

Taking into account the fact that this study is multi-centric and considering that $10 \%$ of the randomized patients are likely not to fulfill the criteria of the per protocol analysis, the total number of the study is therefore 220 patients (110 in each case group).

\section{Version 2.0 of April 29, 2014 J-L Quesada (Protocol version 8.0-29/04/2014):}

This study will involve a sample size of 198 patients (99 patients per group). In order to guarantee this number of analyzable patients, we envisage a complementary recruitment of 10 patients per group. The calculation of the number of patients required corresponds to a noninferiority study design.

The null hypothesis corresponds to a difference in efficacy between treatment groups above the equivalence threshold; The alternative hypothesis allows us to conclude that the treatments are equivalent; 
The primary endpoint is the difference, before / after, of the mean pain score assessed by a numerical scale at inclusion and 30 minutes after administration.

The number of subjects required was assessed by the Schuirmann method ${ }^{26}$, taking into account a minimal, clinically significant value of pain level evolution defined a priori as a modification of 1.3 of the numerical scale (EN) ${ }^{24}$, an alpha risk of $2.5 \%$ and a standard deviation of the response of $2.8^{27}$.

A total of 99 subjects per group will thus be necessary to reject the null hypothesis of a difference in efficacy and to conclude that the evaluated treatment is not inferior compared to the reference treatment, in terms of the evolution of $\mathrm{EN}$ in the first 30 minutes, with a power of $80 \%$.

This calculation was performed using the NQuery Advisor software version 7.0 (Statistical Solutions Ltd., Boston MA, USA).

\section{Post-hoc analysis of the power of the study:}

The recruitment was lower than expected over the planned duration of the study and the power remained above $80 \%$ with an effective standard deviation in reduction in pain by 2.1 in post-hoc analysis.

\section{2 - Framework}

The adopted test framework is based on non-inferiority hypothesis.

$\underline{13 a-S t a t i s t i c a l ~ i n t e r i m ~ a n a l y s e s ~ a n d ~ s t o p p i n g ~ g u i d a n c e ~-~ I n f o r m a t i o n ~}$

No statistical interim was performed.

$\underline{13 b}$ - Statistical interim analyses and stopping guidance - planned adjustment

Not applicable.

$\underline{13 c-\text { Statistical interim analyses and stopping guidance - Details of guidelines }}$

Not applicable.

$\underline{14-\text { Timing of outcome analysis }}$ 
The statistical plan analysis (SAP) for the final analysis of the trial was developed prior to database lock. The SAP will be reviewed and approved by an independent methodological comity and the principal investigator.

\section{5 - Timing of outcome assessments}

The parameters and scale were evaluated at different visits in accordance with the following table.

\begin{tabular}{|c|c|c|c|c|c|c|c|}
\hline & $\begin{array}{c}\text { Inclusion } \\
\text { Randomisation } \\
\text { TO }\end{array}$ & T10 & T20 & T30 & $\mathrm{T} 40$ & T50 & \\
\hline - Inclusion / exclusion criteria check & $\square$ & & & & & & \\
\hline - Patient consent & $\nabla$ & & & & & & \\
\hline - Demographic parameters. & $\nabla$ & & & & & & \\
\hline $\begin{array}{l}\text { - numerical scale of self-evaluation of } \\
\text { pain (EN) }\end{array}$ & $\nabla$ & $\nabla$ & $\square$ & $\square$ & $\square$ & $\square$ & \\
\hline - Non-invasive blood pressure & $\nabla$ & 甲 & $\nabla$ & $\nabla$ & $\square$ & $\nabla$ & \\
\hline - Heart rate and respiratory rate & $\nabla$ & $\nabla$ & $\nabla$ & $\nabla$ & $\nabla$ & $\nabla$ & \\
\hline - Sedation score & $\nabla$ & $\nabla$ & $\square$ & $\nabla$ & $\nabla$ & $\nabla$ & \\
\hline - Oxygen saturation and flow & $\nabla$ & $\nabla$ & $\square$ & $\square$ & & & \\
\hline - The sedation scale & $\nabla$ & $\nabla$ & v & 田 & & & \\
\hline - Injected and sprayed volumes & v & 曰 & $\nabla$ & & & & \\
\hline - Co-analgesia & & & & & & & $\nabla$ \\
\hline - Adverse Events & & & & & & & $\square$ \\
\hline
\end{tabular}

\section{Statistical Principles}

16 - Confidence intervals and $P$ values - Level of statistical significance

The threshold $\mathrm{p} \leq 0.025$ will be taken into account to define the significance of the statistical tests.

\section{7 - Confidence intervals and $\mathrm{P}$ values - Description}

No adjustment for multiplicity will be taken into account.

\section{8 - Confidence intervals and $\mathrm{P}$ values - Confidence intervals to be reported}

The exact method will be taken into account to calculate the confidence interval. 
Adherence to the protocol will be defined as compliance with the criteria for inclusions and exclusions of the protocol and adherence to treatment.

Premature discontinuation of study treatment will be considered as a non-adherence to the protocol.

$19 \mathrm{~b}$ - Adherence and protocol deviations - Description of adherence

Adherence to the protocol will be listed in the CONSORT flow diagram.

$\underline{19 d-A d h e r e n c e ~ a n d ~ p r o t o c o l ~ d e v i a t i o n s ~-~ D e s c r i p t i o n ~ o f ~ p r o t o c o l ~ d e v i a t i o n s ~ t o ~ b e ~ s u m m a r i z e d ~}$ Premature discontinuation of study treatment will be recorded as a protocol deviation and listed in the CONSORT flow diagram.

\section{$\underline{20-\text { Analysis populations }}$}

The PP population will consist of all randomized patients without any major deviation from the protocol. The following deviations from protocol will lead to exclusion from the PP population:

- Subject withdrawing consent to participate in the study.

- Non-adherence to the protocol (Overdosing, underdosing, discontinued intervention).

- No respect of inclusion criteria.

The ITT population will consist of all patients who have been randomized. Patients will be analyzed in the study arm assigned.

\section{Trial Population}

\section{$\underline{21-\text { Screening data }}$}

Numbers of patients assessed for eligibility with acute traumatic pain will be presented in the CONSORT flow Diagram.

\section{$\underline{22-\text { Eligibility }}$}

All adults presenting to the emergency department with pain due to recent trauma and selfrated intensity $\geq 6$ on the numeric pain scale.

This pain can be either permanent or triggered or aggravated paroxysmally by movements or mobilizations.

Proposed subjects for the study will meet each of the following criteria: 
- Age between 18 and 75 years.

- Person affiliated with social security or beneficiary of such a scheme.

- Informed and written consent signed by the patient or their legal representative.

Subjects that meet at least one of the following criteria cannot be included:

- Age under 18 years or upper 75 years.

- Severe traumatized patient of grade A or B (cf Annex 6 classification TREUNAU).

- Pain of medical origin (eg chest pain, abdominal pain, headache ...).

- History of chronic respiratory, renal or hepatic insufficiency.

- Substance addiction.

- Pregnant woman / breastfeeding.

- History of medico-surgical sinus.

- $\quad \mathrm{SpO} 2<90 \%$.

- Systolic blood pressure $<90 \mathrm{mmHg}$.

- Opioid Allergy.

- Patient with head trauma and neurological involvement (GCS score <14).

- Patient with facial massive trauma.

- Patient unable to understand or score pain EN.

- Patient who received an analgesic-type analgesic (level 3) within 6 hours before taking charge.

- ALR indication.

- Obstruction of nasal passages treated with nasal decongestants (particularly oxymetazoline) within 20 minutes of admission.

- Protected persons referred to in Articles L1121-5 to L1121-8 of the CSP.

- Uncontrolled epilepsy.

- Intracranial hypertension.

- Weight upper 100kg.

\section{$\underline{23-\text { Recruitment }}$}

Numbers of patients and reasons for withdrawal and/or exclusion from analysis will be presented in the CONSORT flow diagram.

\section{4a - Withdrawal / follow-up - Level}

Timing of withdrawals and patients lost to follow up will be presented. 
ALGOFINE-2 - Intranasal Sufentanil analgesia versus Morphine intravenous in Emergency room

Statistical analysis plan

\section{4b - Withdrawal / follow-up - Timing / Lost of follow-up data}

Timing of withdrawals and patients lost to follow up will be presented in CONSORT diagram format, with numbers and reasons for withdrawal and/or exclusion from analysis.

\section{4c - Withdrawal / follow-up - Reasons and details}

The reasons and details of the withdrawal / follow-up data presentation will be listed by categories (inadequate concentration in packaging kits, not meeting inclusion criteria, overdosing, underdosing, discontinued intervention).

25a - Baseline patient characteristics - List of baseline patient characteristics to be summarized Patients will be describe at inclusion by age, gender, weight, trauma area (Head, shoulder, Arm/ elbow, Wrist / hand, Thorax wall, Rachis, Pelvis / hip, Leg / knee, Ankle or foot) vital parameters (Heart Rate, Respiratory Rate, Mean Arterial Pressure, numerical Rating Scale for pain), Co-analgesia ( paracetamol, Codeine, Ketoprofen).

\section{$\underline{25 b}$ - Baseline patient characteristics - Details}

Baseline and demographic characteristics will be summarized for PP population. Descriptive summary statistics will be used for reporting continuous (arithmetic median and Inter Quartile Rate) and categorical (numbers and percentages) variables. 
ALGOFINE-2 - Intranasal Sufentanil analgesia versus Morphine intravenous in Emergency room

Statistical analysis plan

\section{Analysis}

$\underline{26 a-O u t c o m e ~ d e f i n i t i o n s ~-~ s p e c i f i c a t i o n s ~ a n d ~ t i m i n g ~}$

See section 15 « Timing of outcome assessments".

\section{$\underline{26 b}$ - Outcome definitions - measurement and units}

Not applicable

\section{$\underline{26 \mathrm{c} \text { - Outcome definitions - transformation used }}$}

Not envisaged.

\section{$\underline{27 a-\text { Analysis methods - presentation }}$}

- Principal objective analysis :

The main objective is to compare the efficacy of analgesia after $30 \mathrm{~min}$ performed by intranasal Sufentanil compared to the reference treatment (Intravenous Morphine).

Outcome: The analysis criterion corresponds to the variation of the numerical scale of the pain (EN at T30 - EN at T0) between the reference treatment (Morphine IV) and the tested treatment (Sufentanil IN).

Population of analysis: The analysis of the main objective will focus on the per-protocol (PP) population, that is to say on all patients included hospitalized in emergencies without major violation to the protocol integrating in particular patients who received the treatment dose provided for in protocol.

Analysis: The non-inferiority of the study treatment compared to the reference treatment in terms of variation of the numerical scale of pain (EN at T30 - EN at T0) will be evaluated using a one sided mean-equivalence $t$ test on the per protocol population. We used the TOSTT procedure (Dinno A. 2015. tostt: mean-equivalence t tests, Stata software package) that tests the equivalence of means in a symmetric equivalence interval using the two-tailed unilateral test approach (Schuirmann 1987) ${ }^{26}$.

The equivalence threshold corresponds to the minimal, clinically significant, change in the level of pain; It has been defined a priori as a modification of 1.3 of the numerical scale $(\mathrm{EN})^{24}$.

The statistical threshold of significance will be $\mathrm{p}<0.025$. 
- Secondary objectives analysis :

- The objective $n^{\circ} 2$ is to compare the efficacy of analgesia performed by intranasal Sufentanil compared to the reference treatment (IV Morphine) after $10 \mathrm{~min}$ and $20 \mathrm{~min}$ of treatment.

Outcome: The analysis criterion corresponds to the variation of the numerical scale of the pain (EN at T10 or T20 - EN at T0) of each treatment (Sufentanil IN versus Morphine IV).

Population of analysis: The analysis will be carried out on the per-protocol (PP) population and then on the intention-to-treat (ITT) population of patients hospitalized in the emergency department.

Analysis: The evaluation of the efficacy of analgesia of pain at intermediate times will be carried out between treatment groups.

The comparative analysis of the variation of the numerical scale of the pain (EN at T10 or T20 - EN at T0) will be carried out using the two group Student t test (a two-sided test). The statistical threshold of significance will be $\mathrm{p}<0.05$.

- The objective $\mathrm{n}^{\circ} 3$ is to evaluate the efficacy of analgesia performed by intranasal Sufentanil and Morphine IV, after $10 \mathrm{~min}$ and $20 \mathrm{~min}$ of treatment.

Outcome: The analysis criterion corresponds to the measurement of the numerical scale (EN) of pain at the initial and final times (EN evaluated at 10 and $20 \mathrm{~min}$ ) in each of the treatment groups (Sufentanil IN versus Morphine IV).

Population of analysis: The analysis will be carried out on the per-protocol (PP) population and then on the intention-to-treat (ITT) population of patients hospitalized in the emergency department.

Analysis: The evaluation of the effectiveness of analgesia of pain at each intermediate time will be performed according to the treatment group.

The comparative analysis of the measurement of the numerical scale of the pain (10 or 20 min) will be carried out using the Student's test for paired series in each group (a two-sided test). The statistical threshold of significance will be $p<0.05$.

- The objective $\mathrm{n}^{\circ} 4$ is to compare the occurrence of adverse effects between treatment groups (Sufentanil IN versus Morphine IV).

Outcome: The analysis criterion corresponds to the evaluation of the following adverse effects in each of the treatment groups: Nausea, vomiting, epistaxis, discomfort in the nasal 
passages, deep sedation (sedation scale $>2$ ), desaturation $<90 \%$, pressure arterial $<90 \mathrm{mmHg}$, respiratory rate $<10 / \mathrm{min}$, use of Naloxone (antidote).

Population of analysis: The analysis will be carried out on the per-protocol (PP) population and then on the intention-to-treat (ITT) population of patients hospitalized in the emergency department.

Analysis: The comparative analysis of adverse effects between treatment groups (Sufentanil IN versus Morphine IV) will be performed using the chi-2 test and by an exact Fisher test when the expected value of a contingency table cell will be less than 5 .

The statistical threshold of significance will be $\mathrm{p}<0.05$.

- The objective $\mathrm{n}^{\circ} 5$ is to evaluate the feasibility in pre-hospitalized patients.

The objective is to evaluate efficacy of analgesia performed by intranasal Sufentanil compared to the reference treatment (IV Morphine) after $10 \mathrm{~min}, 20 \mathrm{~min}$ and $30 \mathrm{~min}$ of treatment in the group of pre-hospital patients. The objective is to evaluate patient satisfaction.

Outcome: The analysis criterion corresponds to the variation of the numerical scale of the pain (EN at $10 \mathrm{~min}, 20 \mathrm{~min}$ and $30 \mathrm{~min}-\mathrm{EN}$ at T0) of each treatment (Sufentanil IN versus Morphine IV).

Population of analysis: The analysis will be performed on the pre-hospital patient group of 30 subjects.

Planned analysis: A descriptive evaluation of the effectiveness of analgesia of pain at each time and the satisfaction of the patient with regard to its management will be carried out between treatment groups. The comparative analysis of the variation of the numerical scale of the pain (EN at $10 \mathrm{~min}, 20 \mathrm{~min}$ and $30 \mathrm{~min}-\mathrm{EN}$ at $\mathrm{T} 0$ ) will be carried out using a repeated measures analysis of variance integrating if necessary the correction from Greehouse-Geisser;

The recruitment of patients in the pre-hospital group is not sufficient to achieve this goal.

\section{$\underline{27 b-\text { Analysis methods - adjustment for covariates }}$}

- Principal outcome analyzes (secondary objectives) :

The reviewer of the manuscript proposed to complete the analysis with a linear regression that adjusts for baseline pain score and site (as a stratification variable) to give a more precise treatment effect estimation.

$\underline{27 c-\text { Analysis methods -assumptions to be checked }}$ 
ALGOFINE-2 - Intranasal Sufentanil analgesia versus Morphine intravenous in Emergency room

Statistical analysis plan

The parameters normality will be checked using Shapiro Wilks test.

The variances homogeneity will be checked using test on the equality of standard deviations.

$\underline{27 d-\text { Analysis methods - alternative methods }}$

- Principal outcome analyzes :

The reviewer of the manuscript proposed to complete the analysis with a linear regression that adjusts for baseline pain score and site (as a stratification variable) to give a more precise treatment effect estimation.

- Principal outcome analyzes (complementary analysis) :

The superiority of intra-nasal Sufentanil compared to the reference treatment will be evaluated using a two sample Student t test after verification of the application conditions.

However, in the case where the application conditions were not respected, a non-parametric Mann-Whitney test, considered robust, was considered as a possible alternative.

- Secondary outcome analyzes (secondary objectives):

- The objective $\mathrm{n}^{\circ} 2$ is to compare the efficacy of analgesia performed by intranasal Sufentanil compared to the reference treatment (IV Morphine) after $10 \mathrm{~min}$ and $20 \mathrm{~min}$ of treatment.

The efficacy of intra-nasal Sufentanil compared to the reference treatment will be evaluated using a non-parametric Mann-Whitney test, considered robust, when the application conditions of the two group Student $t$ test will not be respected.

- The objective $n^{\circ} 3$ is to evaluate the efficacy of analgesia performed by intranasal Sufentanil and Morphine IV, after $10 \mathrm{~min}$ and $20 \mathrm{~min}$ of treatment.

The comparative analysis of the measurement of the numerical scale of the pain $(10$ or 20 min) compared to baseline will be performed using a non-parametric Wilcoxon test when the application conditions of the Student's test for paired series will not be respected.

- The objective $\mathrm{n}^{\circ} 4$ is to compare the occurrence of adverse effects between treatment groups (Sufentanil IN versus Morphine IV).

The comparative analysis of the adverse effects between treatment groups (Sufentanil IN versus Morphine IV) will be performed using an exact Fisher test when the expected value of a contingency table cell will be less than 5 . 
- The objective $\mathrm{n}^{\circ} 5$ is to evaluate the feasibility in pre-hospitalized patients.

The comparative analysis of patient satisfaction will be performed using a non-parametric Mann-Whitney test when the normality or homogeneity of the variances is rejected.

$\underline{27 e-\text { Analysis methods - planned subgroup analyses }}$

No subgroup analysis is considered for the randomized trial analysis.

\section{8 - Missing Data}

- Recoding Primary criteria:

Implementation of the modified ITT analysis required the replacement of missing data; this was performed using the multiple imputation method. Ten imputations of the missing data were taken into account in the multiple imputation process.

- Recoding Secondary and exploratory criteria:

No data replacement was considered.

\section{9 - Additional analyses}

- Principal outcome analyzes (sensibility analysis) :

Sensitivity analysis of the primary objective: The evaluation of the non-inferiority of intranasal Sufentanil compared to the reference treatment conducted on the per-protocol population (PP) will be confirmed on the intention-to-treat population (ITT) in sensitivity analysis to comply recommendations of the guidelines (JAMA, 2012). This will be evaluated using a Schuirmann test on the imputed data. This analysis will retain the $2.5 \%$ as the statistical threshold.

In practice for a more robust result, both analyzes (PP and ITT) must be performed and give similar results.

- Principal outcome analyzes (complementary analysis) :

The evaluation of the superiority of intra-nasal Sufentanil compared to the reference treatment is used in hierarchical analysis. This will be evaluated on the intention to treat analysis using a two sample Student $t$ test after verification of the application conditions.

Although unilateral testing appears to be most consistent with therapeutic hypotheses, we used a two-sided test. By decreasing the risk of alpha error on the conclusion of superiority, a two-sided test is more conservative.

This analysis will retain the $5 \%$ as a statistical threshold. This analysis will not require adjustment of the statistical threshold. 
ALGOFINE-2 - Intranasal Sufentanil analgesia versus Morphine intravenous in Emergency room

Statistical analysis plan

$\underline{30-\text { Harms }}$

The safety data will be summarized by the frequency of events.

\section{$\underline{31-\text { Statistical software }}$}

Statistical analysis will be performed using STATA® Software Version 14.2 or higher (Stata Corporation 4905 Lakeway Drive College Station, TX 77845 USA).

\section{$\underline{32 a}$ - References - for non-standard statistical methods}

Not applicable

\section{$\underline{32 b-R e f e r e n c e s ~ t o ~ D a t a ~ M a n a g e m e n t ~ P l a n ~}$}

The data consistency check was performed during the data entry on Redcap and the blind review preparation.

\section{$\underline{32 c-\text { References to the Trial Master File }}$}

The Clinical Research Department (DRCI) of the University Hospital Center of Grenoble Alps (CHUGA) was in charge of maintaining and storing documents related to the "Algofine2 " clinical trial.

The Trial Master File is available from the DRCI under the reference 38RC13.558; This information is archived on the DRCI server.

\section{$32 \mathrm{~d}$ - References to other standard}

RCDMS.MOP.009 - GEL D'UNE BASE DE DONNEES.

RCDMS.FOR.012 - CERTIFICAT DE GEL DE BASE DE DONNEES.

Gamble C, Krishan A, Stocken D, Lewis S, Juszczak E, Doré C, Williamson PR, Altman DG, Montgomery A, Lim P, Berlin J, Senn S, Day S, Barbachano Y, Loder E. Guidelines for the Content of Statistical Analysis Plans in Clinical Trials. JAMA. 2017; 318(23):2337-2343. 
ALGOFINE-2 - Intranasal Sufentanil analgesia versus Morphine intravenous in Emergency room

Statistical analysis plan

\section{Appendix I}

\section{Template of table of descriptive analysis at the inclusion visit}

Table 1 - Baseline characteristics of participants

\begin{tabular}{|c|c|c|c|}
\hline & & $\begin{array}{l}\text { Groupe } 1 \\
n=X X X\end{array}$ & $\begin{array}{l}\text { Groupe } 2 \\
n=X X X\end{array}$ \\
\hline Age & median [IQR] & & \\
\hline Gender (Men) & Frequency(number) & & \\
\hline Weight & median [IQR] & & \\
\hline \multicolumn{4}{|l|}{ Trauma area } \\
\hline Head & Frequency(number) & & \\
\hline Shoulder & Frequency(number) & & \\
\hline Arm / elbow & Frequency(number) & & \\
\hline Wrist or hand & Frequency(number) & & \\
\hline Thorax wall & Frequency(number) & & \\
\hline Rachis & Frequency(number) & & \\
\hline Pelvis / hip & Frequency(number) & & \\
\hline Leg / knee & Frequency(number) & & \\
\hline Ankle or foot & Frequency(number) & & \\
\hline \multicolumn{4}{|c|}{ Vital Parameters at inclusion } \\
\hline $\mathrm{HR}$ (per min) & median [IQR] & & \\
\hline $\mathrm{RR}$ (per min) & median $[\mathrm{IQR}]$ & & \\
\hline $\mathrm{SpO}_{2}(\%)$ & median [IQR] & & \\
\hline MAP (mmHg) & median [IQR] & & \\
\hline NRS (/10) & median [IQR] & & \\
\hline \multicolumn{4}{|l|}{ Co-analgesia } \\
\hline Paracetamol & Frequency(number) & & \\
\hline Codeine & Frequency(number) & & \\
\hline Ketoprofen & Frequency(number) & & \\
\hline
\end{tabular}


ALGOFINE-2 - Intranasal Sufentanil analgesia versus Morphine intravenous in Emergency room Statistical analysis plan

Templates of table of the principal outcomescales analysis between the inclusion (TO) and the visit at T30 and between groups.

Table 2 - Criteria between T0 and T30

\begin{tabular}{lcccc}
\hline Scale EN & $\begin{array}{c}\text { Group 1 } \\
(\mathrm{n}=\mathrm{XXX})\end{array}$ & $\begin{array}{c}\text { Group 2 } \\
(\mathrm{n}=\mathrm{XXX})\end{array}$ & $\begin{array}{c}\text { Delta G1-G2 } \\
\text { mean } \pm \text { se [IC95\%] } \\
\text { Effect Size [IC95\%] }\end{array}$ & $\begin{array}{c}\mathrm{p} \\
\text { value }\end{array}$ \\
\hline Delta EN T30-T0 & mean \pm SD & mean \pm SD & $\begin{array}{c}\text { mean } \pm \text { SD [CI], } \\
\text { Cohen's d Effect Size [CI] }\end{array}$ & $\begin{array}{c}\mathrm{P} \\
\text { value }^{(5)}\end{array}$
\end{tabular}

Results expressed as mean \pm standard deviation [95\% CI], Cohen's d Effect Size [95\% CI]

(5) $\mathrm{p}$ based on an Student two sample T test.

Templates of tables of scales analysis between the inclusion (T0) and the visit at T10 or T20 and between groups.

Table 3 - Criteria between $\mathrm{T} 0$ and $\mathrm{T} 10$ or T20

\begin{tabular}{lcccc}
\hline Scale EN & $\begin{array}{c}\text { Group 1 } \\
(\mathrm{n}=\mathrm{XXX})\end{array}$ & $\begin{array}{c}\text { Group 2 } \\
(\mathrm{n}=\mathrm{XXX})\end{array}$ & $\begin{array}{c}\text { Delta G1-G2 } \\
\text { mean } \pm \mathrm{se} \\
{[\mathrm{IC} 95 \%]}\end{array}$ & $\begin{array}{c}\mathrm{p} \\
\text { value }\end{array}$ \\
\hline Delta EN T10-T0 & mean $\pm \mathrm{SD}$ & mean $\pm \mathrm{SD}$ & $\begin{array}{c}\text { mean } \pm \mathrm{SD}[\mathrm{CI}], \\
{[\mathrm{IC95 \%}]}\end{array}$ & $\begin{array}{c}\mathrm{P} \\
\text { value }^{(5)}\end{array}$ \\
\hline Delta EN T20-T0 & mean $\pm \mathrm{SD}$ & mean $\pm \mathrm{SD}$ & mean $\pm \mathrm{SD}[\mathrm{CI}]$, & $\mathrm{P}$ \\
& & & {$[\mathrm{IC95 \% ]}$} & value $^{(5)}$ \\
\hline
\end{tabular}

Results expressed as mean \pm standard deviation $[95 \% \mathrm{CI}]$

(5) $\mathrm{p}$ based on an Student two sample T test.

Templates of tables of scales analysis between the inclusion (T0) and the visit at $\mathrm{T} 10$ by groups.

Table 4 - Criteria between T0 and T10

\begin{tabular}{|c|c|c|c|c|}
\hline Scale EN & T0 & $\mathrm{T} 10$ & $\begin{array}{c}\text { Delta T10-T0 } \\
\text { Effect Size [IC95\%] }\end{array}$ & $\begin{array}{c}\mathrm{p} \\
\text { value }\end{array}$ \\
\hline $\begin{array}{l}\text { Groupe } 1 \\
(n=X X X)\end{array}$ & mean $\pm \mathrm{SD}$ & mean $\pm \mathrm{SD}$ & $\begin{array}{c}\text { mean } \pm \mathrm{SD}[\mathrm{CI}] \\
{[\mathrm{IC} 95 \%]}\end{array}$ & $P$ value ${ }^{(5)}$ \\
\hline $\begin{array}{l}\text { Groupe } 2 \\
(n=X X X)\end{array}$ & mean $\pm \mathrm{SD}$ & mean $\pm \mathrm{SD}$ & $\begin{array}{c}\text { mean } \pm \mathrm{SD}[\mathrm{CI}] \\
{[\mathrm{IC} 95 \%]}\end{array}$ & $P$ value $e^{(5)}$ \\
\hline
\end{tabular}


ALGOFINE-2 - Intranasal Sufentanil analgesia versus Morphine intravenous in Emergency room

Statistical analysis plan

Templates of tables of scales analysis between the inclusion (T0) and the visit at T20 by groups.

Table 5 - Criteria between $\mathrm{T} 0$ and T20

\begin{tabular}{|c|c|c|c|c|}
\hline Scale EN & T0 & $\mathrm{T} 20$ & $\begin{array}{c}\text { Delta T20-T0 } \\
\text { Effect Size [IC95\%] }\end{array}$ & $\begin{array}{c}\mathrm{p} \\
\text { value }\end{array}$ \\
\hline $\begin{array}{l}\text { Groupe } 1 \\
(n=X X X)\end{array}$ & mean $\pm \mathrm{SD}$ & mean $\pm \mathrm{SD}$ & $\begin{array}{c}\text { mean } \pm \text { SD }[\mathrm{CI}] \\
{[\mathrm{IC} 95 \%]}\end{array}$ & $P$ value ${ }^{(5)}$ \\
\hline $\begin{array}{l}\text { Groupe } 2 \\
(n=X X X)\end{array}$ & mean $\pm \mathrm{SD}$ & mean $\pm \mathrm{SD}$ & $\begin{array}{c}\text { mean } \pm \mathrm{SD}[\mathrm{CI}] \\
{[\mathrm{IC} 95 \%]}\end{array}$ & $P$ value $e^{(5)}$ \\
\hline
\end{tabular}

Results expressed as mean \pm standard deviation $[95 \% \mathrm{CI}]$

(5) $\mathrm{p}$ based on an Student paired sample T test. 
ALGOFINE-2 - Intranasal Sufentanil analgesia versus Morphine intravenous in Emergency room Statistical analysis plan

Template of table of adverse event analysis between groups.

Table 6 -Adverse events observed

\begin{tabular}{|c|c|c|c|}
\hline & $\begin{array}{c}\text { Groupe } 1 \\
n=X X X\end{array}$ & $\begin{array}{c}\text { Groupe } 2 \\
n=X X X\end{array}$ & $\begin{array}{c}\mathrm{p} \\
\text { value }\end{array}$ \\
\hline Severe adverse events & number (Frequency) & number (Frequency) & $\mathrm{p}$ value \\
\hline Hypoxemia $\left(\mathrm{SpO}_{2}<90 \%\right)$ & number (Frequency) & number (Frequency) & $\mathrm{p}$ value \\
\hline Hypotension (SBP <90 mmHg) & number (Frequency) & number (Frequency) & $\mathrm{p}$ value \\
\hline Bradypnea (RR <10/min) & number (Frequency) & number (Frequency) & $\mathrm{p}$ value \\
\hline Anaphylactic shock & number (Frequency) & number (Frequency) & $\mathrm{p}$ value \\
\hline Alteration of consciousness (Ramsay>2) & number (Frequency) & number (Frequency) & $\mathrm{p}$ value \\
\hline Bradycardia (bpm<45/min) & number (Frequency) & number (Frequency) & $\mathrm{p}$ value \\
\hline Naloxone use & number (Frequency) & number (Frequency) & $\mathrm{p}$ value \\
\hline Mild adverse events & number (Frequency) & number (Frequency) & $\mathrm{p}$ value \\
\hline Dizziness & number (Frequency) & number (Frequency) & $\mathrm{p}$ value \\
\hline Hot flushes & number (Frequency) & number (Frequency) & $\mathrm{p}$ value \\
\hline Nausea or vomiting & number (Frequency) & number (Frequency) & $\mathrm{p}$ value \\
\hline Bad taste / smell & number (Frequency) & number (Frequency) & $\mathrm{p}$ value \\
\hline Mild allergic reaction & number (Frequency) & number (Frequency) & $\mathrm{p}$ value \\
\hline Epistaxis / Rhinorrhea & number (Frequency) & number (Frequency) & $\mathrm{p}$ value \\
\hline Hallucinations & number (Frequency) & number (Frequency) & $\mathrm{p}$ value \\
\hline
\end{tabular}

Results expressed in number (Frequency),

Chi2, Fisher's exact test 
ALGOFINE-2 - Intranasal Sufentanil analgesia versus Morphine intravenous in Emergency room

Statistical analysis plan

\section{Appendix II}

\section{Figure 1. Flow chart of patient enrollment}

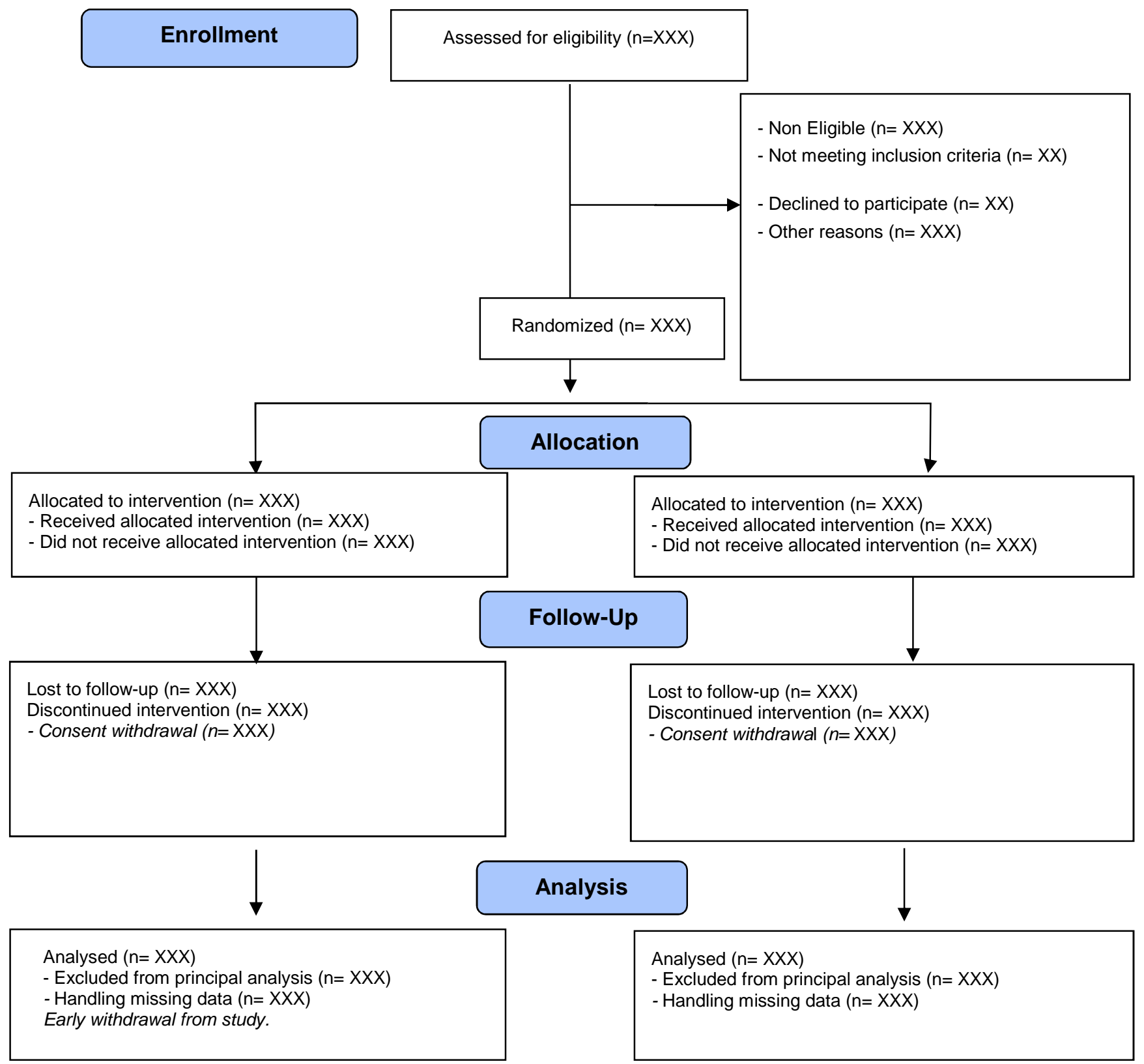

